\title{
Communication
}

\section{Laboratory and Greenhouse Evaluation of Melia volkensii Extracts for Potency against African Sweet Potato Weevil, Cylas puncticollis, and Fall Armyworm, Spodoptera frugiperda}

\author{
Victor Jaoko ${ }^{1,2,3, *(D)}$, Clauvis Nji Tizi Taning ${ }^{1}\left(\mathbb{D}\right.$, Simon Backx ${ }^{2} \mathbb{D}$, Pierfrancesco Motti ${ }^{2}$, Jackson Mulatya ${ }^{3}$, \\ Jan Vandenabeele ${ }^{4}$, Titus Magomere ${ }^{5}$, Florence Olubayo ${ }^{5}$, Sven Mangelinckx ${ }^{2} \mathbb{D}$, Stefaan P. O. Werbrouck ${ }^{6} \mathbb{D}$ \\ and Guy Smagghe ${ }^{1}$ (D)
}

1 Laboratory of Agrozoology, Department of Plants and Crops, Faculty of Bioscience Engineering, Ghent University, Coupure Links 653, B-9000 Ghent, Belgium; tiziclauvis.taningnji@ugent.be (C.N.T.T.); guy.smagghe@ugent.be (G.S.)

2 SynBioC, Department of Green Chemistry and Technology, Faculty of Bioscience Engineering, Ghent University, Coupure Links 653, B-9000 Ghent, Belgium; simon.backx@ugent.be (S.B.); pierfranscesco.motti@ugent.be (P.M.); sven.mangelinckx@ugent.be (S.M.)

3 Kenya Forestry Research Institute, P.O. Box, Nairobi 20412-00200, Kenya; jmulatya@kefri.org

4 Better Globe Forestry, P.O. Box, Nairobi 823-00606, Kenya; jan@betterglobeforestry.com

5 Department of Plant Science and Crop Protection, Faculty of Agriculture, University of Nairobi, P.O. Box, Nairobi 30197-00100, Kenya; magomere.titus@ku.ac.ke (T.M.); olubayo@uonbi.ac.ke (F.O.)

Citation: Jaoko, V.; Taning, C.N.T.; Backx, S.; Motti, P.; Mulatya, J.; Vandenabeele, J.; Magomere, T.; Olubayo, F.; Mangelinckx, S.; Werbrouck, S.P.O.; et al. Laboratory and Greenhouse Evaluation of Melia volkensii Extracts for Potency against African Sweet Potato Weevil, Cylas puncticollis, and Fall Armyworm, Spodoptera frugiperda. Agronomy 2021, 11, 1994. https://doi.org/10.3390/ agronomy11101994

Academic Editor: Gerardo Fernández Barbero

Received: 31 August 2021

Accepted: 28 September 2021

Published: 1 October 2021

Publisher's Note: MDPI stays neutral with regard to jurisdictional claims in published maps and institutional affiliations.

6 Laboratory of Applied In Vitro Plant Biotechnology, Department of Plants and Crops, Faculty of Bioscience Engineering, Ghent University, Valentin Vaerwyckweg 1, B-9000 Ghent, Belgium;

stefaan.werbrouck@ugent.be

* Correspondence: victor.jaoko@ugent.be; Tel.: +254-724-345-063

\begin{abstract}
The African sweet potato weevil, Cylas puncticollis, and fall armyworm, Spodoptera frugiperda, are insect pests of economic importance that have a negative impact on sweet potato and maize production, respectively. In this study, we aimed to evaluate the potential of Melia volkensii extracts to protect sweet potato and maize plants against damage by both insect pests. We evaluated extracts from the bark, leaves, pulp and nuts of Melia volkensii for antifeedant activity against C. puncticollis and S. exigua (used as a substitute for S. frugiperda), under laboratory conditions. Interestingly, extracts of all plant parts showed antifeedant activity. These results led us to investigate the effectiveness of nut and pulp extracts to protect sweet potato and maize crops in greenhouse conditions. Against C. puncticollis, the sweet potato plants treated with nut extracts showed the lowest tuber damage $(18 \%)$ when compared to pulp extracts (30\%), positive control (33\%) and negative control (76\%). Nut extracts, pulp extracts and positive control reduced maize leaf and whorl damage by $S$. frugiperda compared to the negative control. Altogether, this study highlights the potential of M. volkensii extracts and their application in integrated insect pest management
\end{abstract}

Keywords: botanical pesticides; crude extracts; integrated pest management; limonoids; maize leaf damage; sweet potato tuber damage

\section{Introduction}

Insect control products of plant origin could offer more sustainable alternatives to synthetic insecticides because they have low mammalian toxicity and low persistence in the environment [1]. The focus of our study was on Melia volkensii, a drought-tolerant, fast-growing tropical tree species that grows in semi-arid areas of East Africa that is widely used in folk medicine for the treatment of various illnesses, such as diarrhea, pain and skin rashes [2-4]. Aqueous leaf extracts of the tree are also traditionally used to control ticks and fleas [5]. M. volkensii is a suitable dryland agroforestry tree and is a source of highly praised mahogany timber and termite-resistant poles [6]. M. volkensii seed kernel extracts have 
shown antifeedant and growth inhibition activity against several insect pests [7-10]. Insect antifeedant compounds such as salannin, volkensin, 1-tigloyl-trichilinin, 1-cinnamoyltrichilinin and 1-acetyltrichilinin have also been isolated from $M$. volkensii fruits $[7,11]$. Findings of previous studies and indigenous knowledge on $M$. volkensii makes this tree an interesting candidate for exploitation as a potential source of insect control products against insect pests of economic importance in Africa. The African sweet potato weevil (SPW), Cylas puncticollis (Boheman), and fall armyworm (FAW), Spodoptera frugiperda (J.E. Smith), are major insect pests of economic importance for sweet potato and maize farming in Africa, respectively. Significant sweet potato damage and economic losses are caused by C. puncticollis which oviposit in the vines and tubers [10]. These weevils cause up to $100 \%$ yield loss [12-14], and the damage from weevils continues to increase during storage [15]. Their larvae feed and tunnel in the tubers, causing reductions in marketable yield and quality [16]. The tunneling produces terpenes which cause bad odors and bitter taste, rendering the sweet potato unpalatable and unmarketable [17]. The terpenes can affect mammalian liver and lungs [18]. The insect also infests the leaves and flower seeds [19]. Infestation occurs during the dry season when high temperatures crack the soil surface, thereby exposing the tubers. Infestation can also occur through planting vines [17]. Application of parathion and chlorpyrifos insecticides have been used in overcoming weevil infestation on sweet potato, however pesticide residues have been reported [20]. Biopesticides such as azadirachtin and spinosad have been evaluated for their efficacy against the sweet potato weevils in the laboratory, but no studies have been reported on field trials [20].

S. frugiperda is an invasive polyphagous pest causing severe economic damage in maize, cotton, rice and several other crops [13]. It feeds heavily on leaves and can cause up to $100 \%$ yield loss in cereals [21]. Synthetic pesticides have been widely used as a tool in fall armyworm control [22]. However, pest resistance has been a concern, and it leads to more frequent applications, increased product dosage or use of more toxic alternative products, which consequently come at an increased cost and are harmful to the environment [23]. Carbamates, pyrethroids and organophosphates, which are majorly used by African farmers, have faced resistance from the fall armyworms [21]. Moreover, synthetic pesticides have raised concerns about pesticide residues, toxicity to non-target organisms and environmental problems [22,23]. As an alternative, there is a global focus on botanical insect control products that have proven to be effective and are less harmful to humans and the environment [24]. The need to develop safe, effective and agroecologically sustainable products of plant origin for application in integrated pest management (IPM) underscores the overall goal of our research study. In this study, we aimed to evaluate the potential of $M$. volkensii extracts to protect sweet potato and maize against damage by C. puncticollis and S. frugiperda. To achieve this objective, we first evaluated the efficacy of crude extracts from M. volkensii nut, pulp, bark and leaf against C. puncticollis and Spodoptera exigua (Hübner), as a model for $S$. frugiperda, under laboratory conditions. The most promising extracts were then tested under greenhouse conditions for efficacy against the insect pests.

\section{Materials and Methods}

\subsection{Collection and Processing of Plant Materials}

Fresh M. volkensii leaves, nuts, pulp and bark samples were collected from a plantation farm in Kiambere, Kenya. Kiambere is located approximately $187 \mathrm{~km}$ east of Nairobi with coordinates of $0^{\circ} 41^{\prime} 10^{\prime \prime} \mathrm{S} 37^{\circ} 54^{\prime} 55^{\prime \prime} \mathrm{E}$, and is $720 \mathrm{~m}$ above sea level. The plant parts were dried in the shade for 21 days. The dried samples were then pulverized using an electric grinder with an $850 \mu \mathrm{m}$ pore size. The resulting powder of each plant part was extracted in methanol in the ratio of $1: 5(w / v)$ for $48 \mathrm{~h}$ at room temperature. The mixture was then filtered using filter paper (Whatman No. 1). The residue obtained was discarded while the filtrate was pre-concentrated in a rotary evaporator at $35{ }^{\circ} \mathrm{C}$ until near dryness. High vacuum was then used to completely dry the crude extracts. 


\subsection{Preparation of Treatments}

For laboratory bioassays, a stock solution of $10 \%(w / v)$ of crude extract from respective plant parts was prepared in methanol, and serial dilution was performed to make $8 \%, 6 \%$, $4 \%$ and $2 \%$. For greenhouse trials, we used a $2 \%$ concentration $(w / v)$ of $M$. volkensii nut and pulp crude extracts. Crude extracts were first dissolved in methanol and topped up with water ( $96 \%$ of total volume). For the negative control, we used methanol in the laboratory bioassay, while in the greenhouse we used $4 \%$ methanol in water $(v / v)$. For the positive control, we used HABLE 5 WG, a synthetic pesticide which contains emamectin benzoate $50 \mathrm{~g} / \mathrm{kg}$ as the active ingredient and is used locally by farmers to manage S. frugiperda and C. puncticollis infestation.

\subsection{Rearing of Insects}

C. puncticollis and S. exigua larvae were obtained from a continuous insect culture maintained in the Laboratory of Agrozoology at Ghent University, Belgium, for over 4 years. C. puncticollis were reared using sweet potato tubers placed in a plastic container $(10 \times 20 \times 30 \mathrm{~cm})$ in a growth chamber set at $26 \pm 2{ }^{\circ} \mathrm{C}, 60-70 \%$ relative humidity and a 16:8 h (L:D) photoperiod [25]. S. exigua larvae were reared using an artificial diet described by Christiaens et al. [26], and after emergence, the adults were fed on honey solution. S. frugiperda larvae used in the greenhouse trials were obtained from a colony maintained using maize leaf in the entomology laboratory at Kenya Forestry Research Institute in Nairobi, Kenya. The colonies of both Spodoptera species were maintained in a growth chamber at $26 \pm 2{ }^{\circ} \mathrm{C}$ with $75 \%$ relative humidity and a $16 \mathrm{~h}$ light: $8 \mathrm{~h}$ dark photoperiod.

\subsection{Antifeedant Bioassay against C. puncticollis and S. exigua in the Laboratory}

Choice bioassay was used to investigate the antifeedant efficacy of $M$. volkensii extracts. For C. puncticollis, we used sliced sweet potato tubers ( $1 \mathrm{~cm}$ thick), while for S. exigua, we used $9 \mathrm{~cm}^{2}$ of Chinese cabbage leaf disc. Then, $100 \mu \mathrm{L}$ of crude extracts from each plant part at concentrations of $2 \%, 4 \%, 6 \%, 8 \%$ and $10 \%$ was discharged and spread evenly on the respective insect diets, and $100 \mu \mathrm{L}$ of methanol was used as the negative control. The diets were exposed to laminar flow to evaporate the methanol. These bioassays were performed in Petri dishes partitioned into two halves as treatment and control, and insect diets were placed in respective partitions. Ten adult C. puncticollis and five third-instar S. exigua larvae were introduced into the respective Petri dishes. The tests were performed in five replicates with three independent biological repetitions per concentration of each crude extract. The weight of the potato slice was measured after $24 \mathrm{~h}$, while the area of the leaf disc consumed after $8 \mathrm{~h}$ was calculated. We used S. exigua in the laboratory bioassays in Ghent University, Belgium, as a model for $S$. frugiperda, which we later tested in greenhouse conditions in Nairobi, Kenya (where $S$. frugiperda causes significant damage in maize production).

The antifeedant index against $S$. exigua was calculated using the formula described by Akhtar and Isman [27], while the antifeedant index against $C$. puncticollis was calculated using the formula described by Liyun et al. [28], with a slight modification, whereby determination of the number of feeding holes in the tubers was replaced by determination of the weights of treated and untreated tubers after $24 \mathrm{~h}$.

\subsection{Efficacy of M. volkensii Extracts against C. puncticollis and S. frugiperda in Greenhouse Conditions}

Sweet potato vines and maize seeds were planted in plastic planting pots and put in transparent insect cages $(60 \times 60 \times 90 \mathrm{~cm}$; Vermandel, Belgium $)$ in a greenhouse (temperature: minimum of $18{ }^{\circ} \mathrm{C}$ at night and maximum of $28^{\circ} \mathrm{C}$ during daytime; relative humidity of 70-80\%; natural light). For C. puncticollis, 20 adult SPWs were artificially introduced 4 months after planting (period of tuber formation). Three days after infestation, respective treatments described in Section 2.2 were applied by drenching over each potato crown using a watering can. However, methanol was evaporated in laminar flow before application. Five and half months after planting, we harvested the sweet potatoes and 
determined the percentage of tuber damage, as described by Nta and Oku [29]. For each treatment, there were 4 replications and 3 independent repeats.

For S. frugiperda, 5 newly hatched larvae were introduced on each maize plant 6 weeks after planting. As soon as feeding was noted (2 days after infestation), the treatment described in Section 2.2 was sprayed on each plant using a $1 \mathrm{~L}$ hand sprayer. Seven days after treatment, the percentage of whorls damaged was recorded and leaf damage was evaluated using a visual rating scale of $1-9[23,30]$, where $1=$ no damage or few pinholes, and $9=$ most leaves with long lesions and complete damage. For each treatment, there were 4 replications and 3 independent repeats. The experimental set-ups for sweet potato and maize plants are presented in Supplementary Figures S1 and S2, respectively.

\subsection{Statistical Analysis}

All the statistical analyses were conducted using GraphPad Prism version 6.01. Antifeedant indices in the choice bioassays, maize leaf damage, maize whorl damage and sweet potato tuber damage within each treatment were checked for normality (ShapiroWilk test) to assess if data followed a normal distribution [31]. Not all the data for these biological parameters were normally distributed, and we performed the analysis with nonparametric tests. Antifeedant indices from laboratory bioassays were therefore subjected to a Kruskal-Wallis test to perform the analysis of variance followed by the Dunn's test for multiple comparisons between means [32]. To determine significant differences between the different means, we applied the Bonferroni correction, and means were considered significantly different if their $p$-value was greater than the corrected Bonferroni $p$-value [33]. In the greenhouse experiments, we performed the non-parametric Mann-Whitney test to compare significance between the various treatments and the negative control [34].

\section{Results}

3.1. Laboratory Evaluation of Antifeedant Activity of M. volkensii Crude Extracts against C. puncticollis and S. exigua

M. volkensii nut, pulp, bark and leaf extracts (at 2\%, 4\%, $6 \%, 8 \%$ and $10 \%$ concentrations) all showed varying antifeedant activity against adult C. puncticollis and S. exigua larvae, as presented in Supplementary Figures S3 and S4, respectively. The lowest bioactive concentration tested ( $2 \%$ ) recorded antifeedant indices (AFI) above $40 \%$ for all the plant part extracts against both insect species, as presented in Figure 1a,b. Even though there was no significant difference in activity at $2 \%$ concentration of all plant part extracts, the nut and pulp extracts had a higher mean AFI of $51 \%$ each, compared to $43 \%$ and $44 \%$ for bark and leaf extracts respectively, against C. puncticollis. A similar trend was observed in S. exigua, where the nut and pulp extracts showed a higher mean AFI of $57 \%$ and $58 \%$ respectively, compared to $50 \%$ and $48 \%$ for bark and leaf extracts.

\subsection{Antifeedant Activity of M. volkensii Crude Extracts against C. puncticollis in Greenhouse Conditions}

The highest sweet potato tuber damage was observed in the negative control with $76 \%$ tuber damage, as presented in Figure 2. There was a significant reduction in tuber damage in the sweet potato treated with nut extracts, with only $18 \%$ of total tuber damaged compared with the negative control $(\leq 0.0001, n=12)$. We also observed a significant reduction in tuber damage with pulp extract $(p=0.0087, n=12)$ and the positive control $(p=0.0033, n=12)$ when compared with the negative control. The extent of tuber damage was also confirmed visually and is presented in Supplementary Figure S1. 


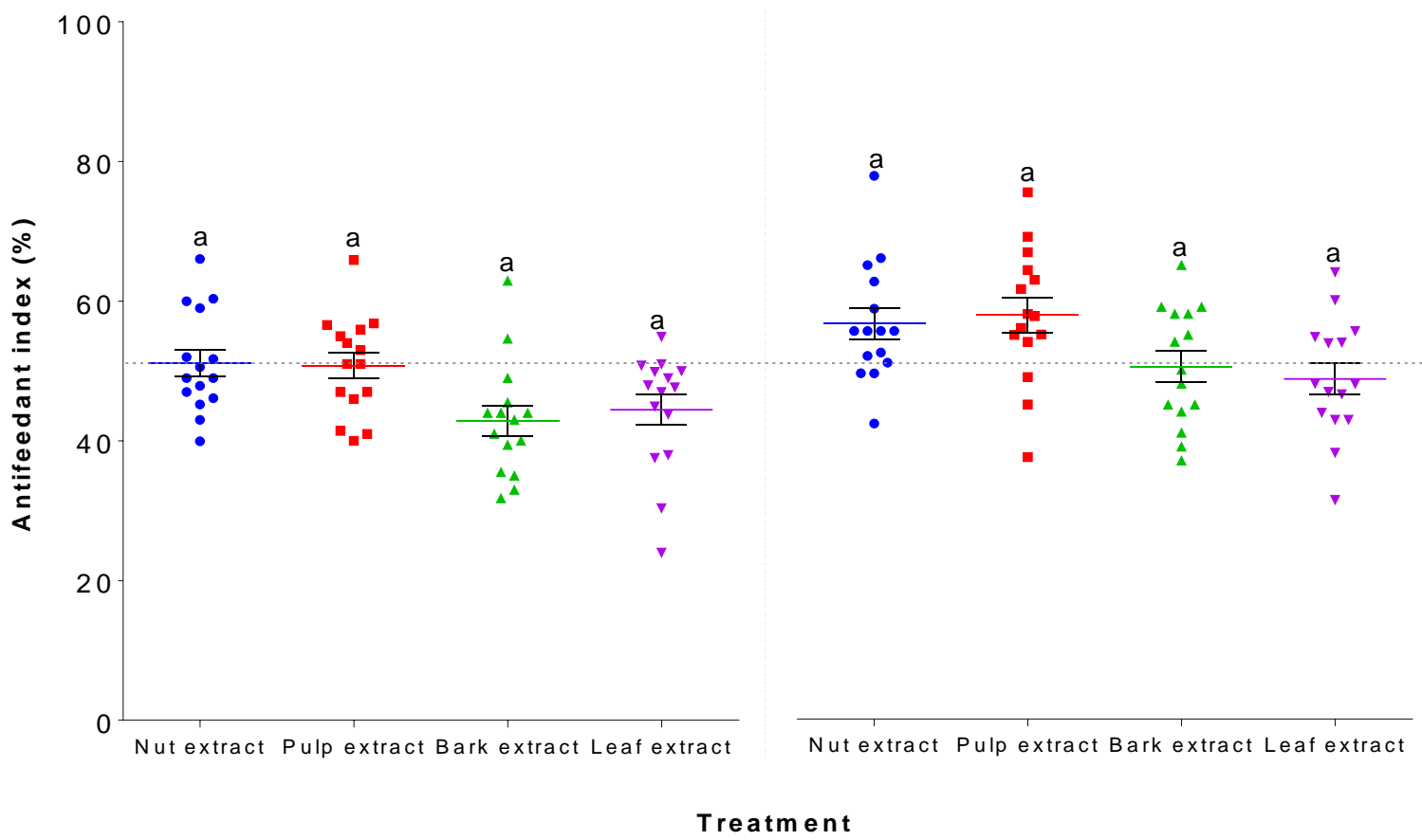

Figure 1. Scatter plot representation of antifeedant index at $2 \%$ concentration of crude extracts from various parts of $M$. volkensii \pm standard error of mean (SEM) with 5 technical repeats and 3 independent biological repeats per plant part against C. puncticollis (a) and S. exigua (b). Means followed by same letter indicate no significant difference after Bonferroni correction (see Section 2.6). Same letter 'a' means that there is no significant difference in antifeedant activity between the different treatments.

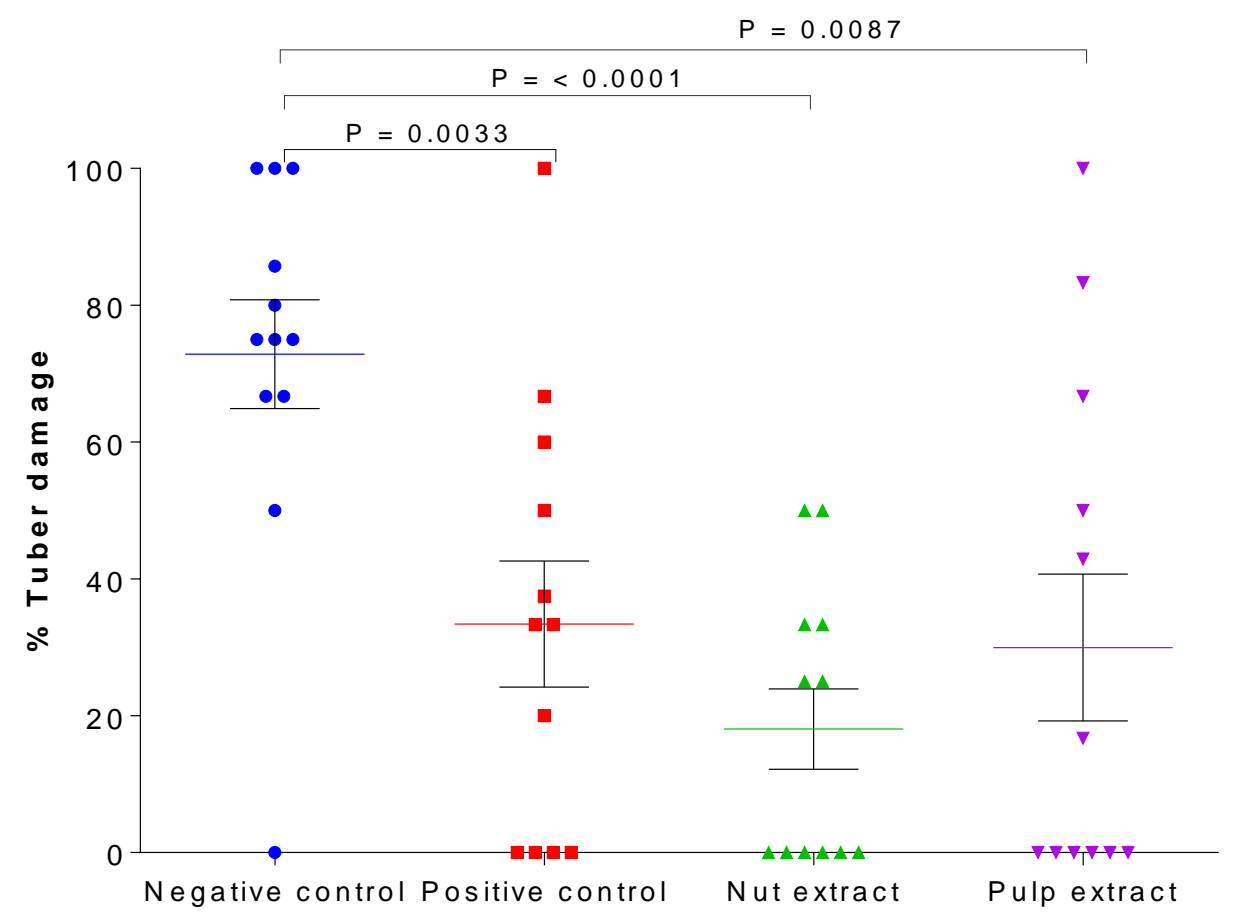

Treatment

Figure 2. Scatter plot representation of sweet potato tuber damage for various treatments \pm SEM with 4 technical repeats and 3 independent biological repeats per treatment. $p$-values, to indicate significant difference, were determined by the Mann-Whitney test. 


\subsection{Antifeedant Activity of M. volkensii Crude Extracts against Spodoptera frugiperda under Greenhouse Conditions}

Maize leaf and whorl damage were characterized by mass of holes on leaves, ragged edges and larval frass. The highest leaf damage (7.6) was observed in the negative control, as presented in Figure 3a. There was a significant reduction in leaf damage in maize treated with the nut extracts (4.5), pulp extracts (5.0) and the positive control (4.6), as compared with the negative control $(p \leq 0.0001, n=12)$. The extent of leaf damage of various treatments was also observed visually, as presented in Supplementary Figure S4. Maize whorl is the growing part of the plant and is the preferred feeding site for FAW. The highest whorl damage was observed in the negative control $(96 \%)$, as presented in Figure $3 \mathrm{~b}$. There was a significant reduction in whorl damage in nut extract (17\%), pulp extract $(35 \%)$ and the positive control (5\%) when compared to the negative control $(p \leq 0.0001, n=12)$.

a) Leaf damage

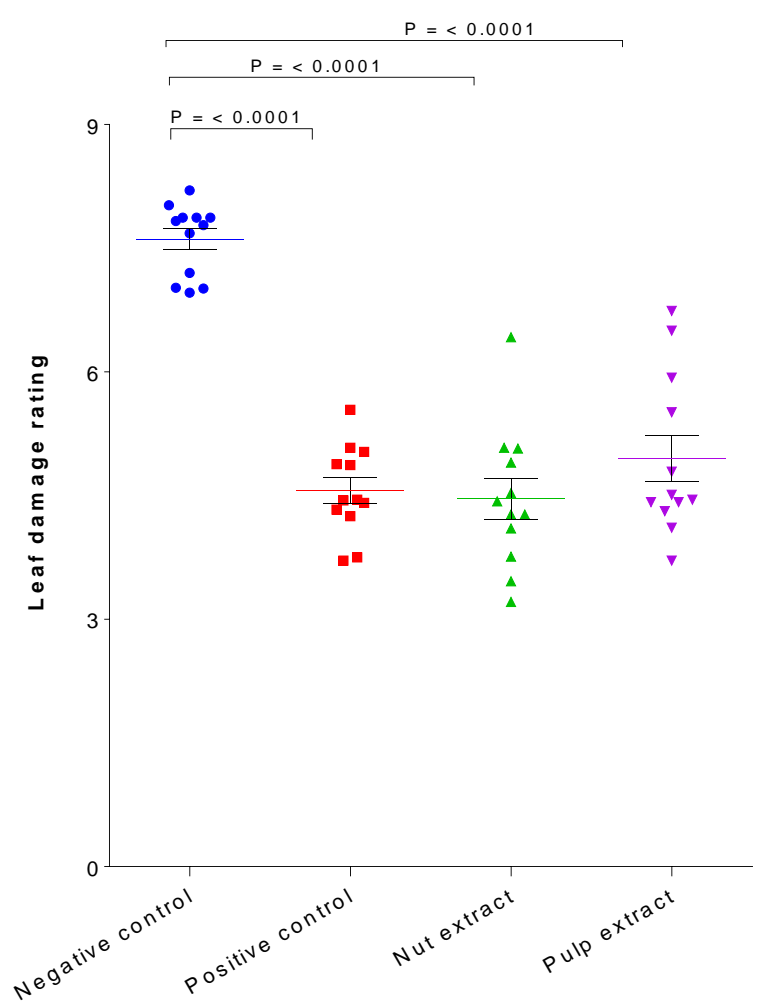

b) Whorl damage

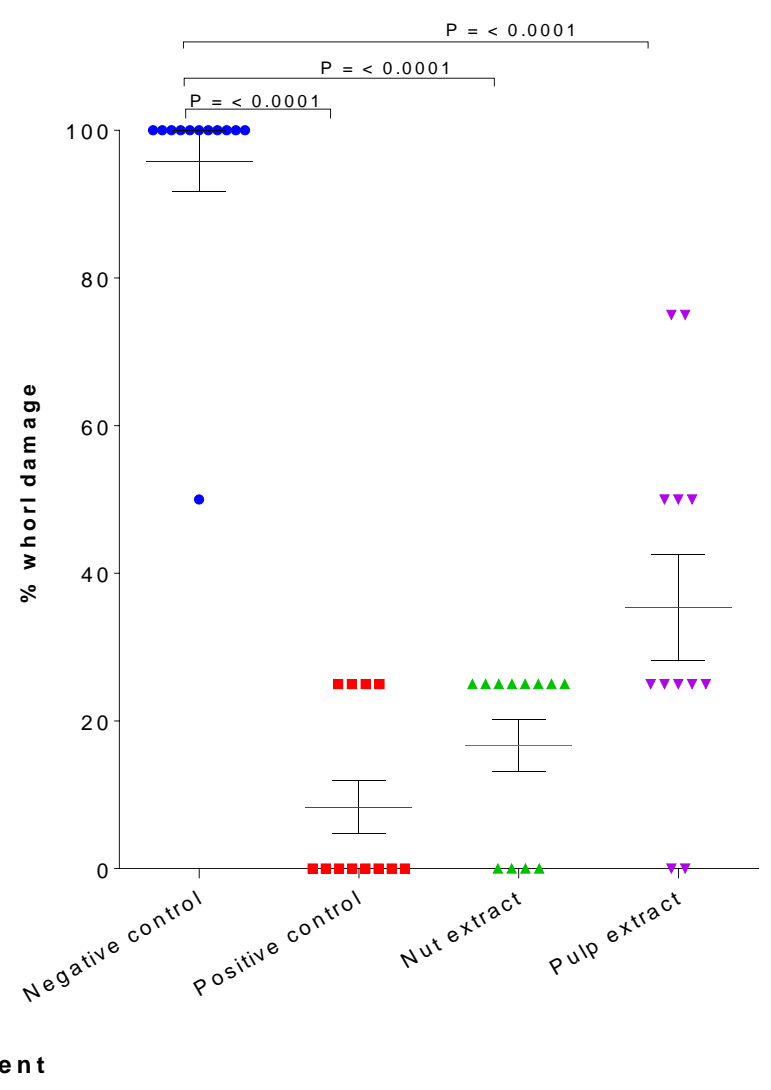

Figure 3. Scatter plot representation of maize leaf damage (a) and whorl (b) damage for various treatments ( $2 \%$ extracts) \pm SEM with 4 technical repeats and 3 independent biological repeats per treatment. $p$-values, to indicate significant difference, were determined by the Mann-Whitney test.

\section{Discussion}

Antifeedants render plants unattractive and unpalatable, thereby reducing plant damage by insect pests [35]. Our laboratory study shows that insect antifeedant compounds are present in the bark, nuts, pulp and leaves of $M$. volkensii. The antifeedant activity observed could be due to the presence of bitter limonoids that make the diet unpalatable to the insects [2]. Some of the limonoids with insect control potential which have reportedly been isolated from $M$. volkensii include $1 \alpha, 3 \alpha$-diacetylvilasinin, 1-cinnamoyltrichilinin, 1-tigloyltrichilinin, 1-acetyltrichilinin, salannin, 1-detigloyl-1-isobutylsalannin, $2^{\prime}, 3^{\prime}$-dihydrosalannin, ohchinin3 -acetate, nimbolin B, volkensin and toosendanin, among others $[9,36]$. Previous studies have also reported that most of these insect antifeedant compounds are isolated from $M$. 
volkensii fruits [7]. This could be an indication that more potent antifeedant compounds could be found in the nut and pulp. In this study, nut and pulp extracts showed higher antifeedant activity as compared to the leaf and bark extracts. In laboratory bioassays, AFI values of crude $M$. volkensii nut and pulp at a $2 \%$ concentration were $57 \%$ and $58 \%$, respectively. When compared with other plant products, clove oil has shown an AFI of $56.9 \%$ at a $1 \%$ concentration [37], while powdered and aqueous extracts of Peumus boldus (Molina) recorded AFI values of $39.6 \%$ and $38.4 \%$ respectively, at a $2 \%$ concentration against S. frugiperda $[38,39]$. Dichloromethane extracts of Duguetia lanceolata stem have exhibited a $\mathrm{LC}_{50}$ of $946.5 \mu \mathrm{g} / \mathrm{mL}$ against the first instar of $S$. frugiperda [40]. Previous laboratory bioassays of pure botanical insecticides pyrethrins, toosendanin, veratrine, matrine, stemonine, rotenone and nicotine showed AFI indices of $97.9 \%, 97.9 \%, 59.4 \%$, $33.9 \%, 69.3 \%, 35.4 \%$ and $39.9 \%$ respectively, against SPW at a $0.2 \%$ concentration [28]. Results from this study show that crude nut and pulp extracts both exhibit an AFI of $51 \%$. This is higher than some of the pure botanical pesticides, despite being at a higher concentration ( $2 \%)$.

Our study shows that crude nut extracts can provide a degree of protection to maize by reducing maize whorl damage by up to $17 \%$ and minimizing leaf damage. Extensive leaf damage by $S$. frugiperda can lead to poor plant health and ultimately reduced maize yield at harvest. Feeding on the whorls of young maize plants could also damage the growing point of the maize, leading to reduced yield, stunted growth or even death of the maize plant. M. volkensii nut extracts could offer maize protection by reducing leaf and whorl damage by $S$. frugiperda. In our greenhouse evaluation of sweet potato protection, the commercial pesticide offered a degree of protection; however, it was not as effective as the nut extracts. In Kenya, where this study was based, there is no registered insecticide specific to SPW, and farmers use other broad-spectrum insecticides such as emamectin benzoate (HABLE $5 \mathrm{wg}$ ) to manage SPW populations. The sweet potato treated with nut extracts showed less tuber damage $(18 \%)$ than the positive control $(33 \%)$ and could offer a better alternative in the control of SPW. Crude extracts from Aframomum melegueta, Dennettia tripetalla and Xylopia aethiopica fruits have shown protection of sweet potato tuber from damage by SPW, with low damage of $11.5 \%, 15.1 \%$ and $10.6 \%$, respectively [41]. Our results from the laboratory bioassays validated in the greenhouse indicate that $M$. volkensii nut and pulp extracts could potentially be an important component in the management of FAW and SPW. It has, however, been reported that repeated exposure of pests to non-toxic antifeedants could potentially lead to habituation or loss of efficacy in pest management [42]. This highlights the importance of combining different control strategies in an IPM approach to prevent pest resistance emergence. In Kenya, M. volkensii nuts, pulp, bark and leaves are readily available and are part of the waste generated during seed extraction, timber processing and pruning. These waste materials could be a useful raw material for the formulation of botanical pesticides, as they contain potential insecticidal compounds. However, products derived from nuts and pulp could be more potent against insect pests. Further phytochemical evaluation of the crude extracts of $M$. volkensii is ongoing to isolate and identify bioactive compounds.

Supplementary Materials: The following are available online at https://www.mdpi.com/article/10 .3390/agronomy11101994/s1, Figure S1: Cylaspuncticollis greenhouse experimental set up and sweet potato tuber damage pictorials, Figure S2: Spodopterafrugiperda greenhouse experimental set up and maize leaf damage pictorials, Figure S3: Cylaspuncticollis laboratory bioassay raw data and analysis, Figure S4: Spodopteraexigua laboratory bioassay raw data and analysis.

Author Contributions: Conceptualization, J.M., G.S., S.P.O.W., T.M., J.V. and F.O.; methodology, V.J., C.N.T.T., S.B., S.M., F.O. and G.S.; formal analysis, V.J., C.N.T.T., G.S.; investigation, V.J., C.N.T.T.; resources, S.P.O.W., G.S., S.M., T.M., F.O.; writing—original draft preparation, V.J.; writing—review and editing, J.M., G.S., S.P.O.W., T.M., J.V., F.O., S.B., P.M., S.M., C.N.T.T.; supervision, G.S., S.M., S.P.O.W., F.O.; project administration, S.P.O.W., T.M., F.O.; funding acquisition, J.M., G.S., S.P.O.W., T.M. and F.O. All authors have read and agreed to the published version of the manuscript. 
Funding: This research was funded by VLIR-UOS [Grant number KE2018TEA465A103].

Institutional Review Board Statement: Not applicable.

Informed Consent Statement: Not applicable.

Data Availability Statement: The data used to support the findings of this study are included in the article and Supplementary Materials.

Conflicts of Interest: The authors declare no conflict of interest.

\section{References}

1. Céspedes, C.L.; Calderón, J.S.; Lina, L.; Aranda, E. Growth inhibitory effects on fall armyworm Spodoptera frugiperda of some limonoids isolated from Cedrela spp. (Meliaceae). J. Agric. Food Chem. 2000, 48, 1903-1908. [CrossRef]

2. Wycliffe, W. Toxicological Studies of Fruit Powder and Extracted Cake of Melia volkensii Guerke (Family: Meliaceae) on Maasai Goats in Kenya. Int. J. Pharm. Chem. 2017, 3, 82-85. [CrossRef]

3. Cantrell, C.L.; Rajab, M.S.; Franzblau, S.G.; Fischer, N.H. Antimycobacterial triterpenes from Melia volkensii. J. Nat. Prod. 1999, 62, 546-548. [CrossRef]

4. Kamau, R.W.; Juma, B.F.; Baraza, L.D. Antimicrobial compounds from root, stem bark and seeds of Melia volkensii. Nat. Prod. Res. 2016, 30, 1984-1987. [CrossRef]

5. Chiu, S.-F.; Rembold, H.; Mwangi, R.W.; Isman, M.B.; Arnason, J.T.; Towers, G.H. Other Meliaceous Plants Containing Ingredients for Integrated Pest. Management and Further Purposes; VCH: Weinheim, Germany, 1995.

6. Mulanda, E.S.; Chuhila, Y.; Awori, R.M.; Adero, M.O.; Amugune, N.O.; Akunda, E.; Kinyamario, J.I. Morphological and RAPDmarker characterization of Melia volkensii (Grke) in vitro plants regenerated via direct and indirect somatic embryogenesis. Afr. J. Biotechnol. 2015, 14, 1261-1274. [CrossRef]

7. Mitchell, P.L.; Thielen, J.B.; Stell, F.M.; Fescemyer, H.W. Activity of Melia volkensii (Meliaceae) extract against southern green stink bug (Hemiptera: Heteroptera: Pentatomidae). J. Agric. Urban. Entomol. 2005, 21, 131-141.

8. Wilps, H.; Nasseh, O.; Rembold, H.; Krall, S. The effect of Melia volkensii extracts on mortality and fitness of adult Schistocerca gregaria (Forskal) (Orth., Cyrtacanthacrinae). J. Appl. Entomol. 1993, 116, 12-19. [CrossRef]

9. Jaoko, V.; Nji Tizi Taning, C.; Backx, S.; Mulatya, J.; Van den Abeele, J.; Magomere, T.; Olubayo, F.; Mangelinckx, S.; Werbrouck, S.P.O.; Smagghe, G. The phytochemical composition of Melia volkensii and its potential for insect pest management. Plants 2020, 9 , 143. [CrossRef]

10. Brookes, D.R.; James, P.; Walter, G.H.; Furlong, M.J. Origins, Divergence, and Contrasting Invasion History of the Sweet Potato Weevil Pests Cylas formicarius (Coleoptera: Brentidae) and Euscepes batatae (Coleoptera: Curculionidae) in the Asia-Pacific. J. Econ. Entomol. 2019, 112, 2931-2939. [CrossRef]

11. Irungu, L.W.; Mwangi, R.W. Effects of a biologically actuve fraction from Melia volkensii on Culex quinquefasciatus. Insect Sci. Its Appl. 1996, 16, 159-162.

12. Rukarwa, R.J.; Prentice, K.; Ormachea, M.; Kreuze, J.F.; Tovar, J.; Mukasa, S.B.; Ssemakula, G.; Mwanga, R.O.M.; Ghislain, M. Evaluation of bioassays for testing Bt sweetpotato events against sweetpotato weevils. Afr. Crop. Sci. J. 2013, 21, 235-244. [CrossRef]

13. Nderitu, J.; Sila, M.; Nyamasyo, G. Effectiveness of Entomopathogenic nematodes against sweet potato weevil (Cylas puncticollis Boheman) under semi-arid conditions in Kenya. J. Entomol. 2009, 6, 145-154. [CrossRef]

14. Alghali, A.; Munde, W. Evaluation of sweet potato clones for resistance to Cylas puncticollis in Sierra leone. Tropicultura 2001, 19, 5-9.

15. Leng, P.H.; Reddy, G.V.P. Bioactivity of selected eco-friendly pesticides against Cylas formicarius (Coleoptera: Brentidae). Florida Entomol. 2012, 95, 1040-1047. [CrossRef]

16. Myers, R.Y.; Sylva, C.D.; Mello, C.L.; Snook, K.A. Biological and Microbial Control Reduced Emergence of Cylas formicarius elegantulus (Coleoptera: Curculionidae) from Sweet Potato Roots by Heterorhabditis indica. J. Econ. Entomol. 2020, 113, 1129-1133. [CrossRef]

17. Reddy, G.V.P.; Zhao, Z.; Humber, R.A. Laboratory and field efficacy of entomopathogenic fungi for the management of the sweetpotato weevil, Cylas formicarius (Coleoptera: Brentidae). J. Invertebr. Pathol. 2014, 122, 10-15. [CrossRef]

18. Braun, A.R.; Van De Fliert, E. Evaluation of the impact of sweetpotato weevil (Cylas formicarius) and of the effectiveness of cylas sex pheromone traps at the farm level in indonesia. Int. J. Pest. Manag. 1999, 45, 101-110. [CrossRef]

19. Ehisianya, C.N.; Ukeh, D.A.; Isah, M.D.; Lale, N.E.S.; Umeozor, O.C. Field Efficacy of Neem Seed Oil and Diazinon in the Management of Sweetpotato Weevil, Cylas puncticollis (Boh.) in South-eastern Nigeria. J. Plant Stud. 2013, 2, 135-144. [CrossRef]

20. Kyereko, W.; Hongbo, Z.; Amoanimaa-Dede, H.; Meiwei, G.; Yeboah, A. The Major Sweet Potato Weevils; Management and Control: A Review. Entomol. Ornithol. Herpetol. Curr. Res. 2019, 8, 218. [CrossRef]

21. Phambala, K.; Tembo, Y.; Kasambala, T.; Kabambe, V.H.; Stevenson, P.C.; Belmain, S.R. Bioactivity of common pesticidal plants on fall Armyworm Larvae (Spodoptera frugiperda). Plants 2020, 9, 112. [CrossRef] 
22. Deshmukh, S.; Pavithra, H.B.; Kalleshwaraswamy, C.M.; Shivanna, B.K.; Maruthi, M.S.; Mota-Sanchez, D. Field Efficacy of Insecticides for Management of Invasive Fall Armyworm, Spodoptera frugiperda (JE Smith) (Lepidoptera: Noctuidae) on Maize in India. Florida Entomol. 2020, 103, 221-227. [CrossRef]

23. Sena, D.G.; Pinto, F.A.C.; Queiroz, D.M.; Viana, P.A. Fall armyworm damaged maize plant identification using digital images. Biosyst. Eng. 2003, 85, 449-454. [CrossRef]

24. Magrini, F.E.; Specht, A.; Gaio, J.; Girelli, C.P.; Migues, I.; Heinzen, H.; Saldaña, J.; Sartori, V.C.; Cesio, V. Antifeedant activity and effects of fruits and seeds extracts of Cabralea canjerana canjerana (Vell.) Mart. (Meliaceae) on the immature stages of the fall armyworm Spodoptera frugiperda (JE Smith) (Lepidoptera: Noctuidae). Ind. Crops Prod. 2015, 65, 150-158. [CrossRef]

25. Prentice, K.; Christiaens, O.; Wamalwa, L.; Ghislain, M.; Gheysen, G.; Smagghe, G. Insecticidal activity of orally delivered dsRNA in field-collected African sweetpotato weevils Cylas puncticollis (Coleoptera, Brentidae) from Uganda and Kenya. IOBC/WPRS Bull. 2018, 131, 85-89.

26. Christiaens, O.; Tardajos, M.G.; Reyna, Z.L.M.; Dash, M.; Dubruel, P.; Smagghe, G. Increased RNAi efficacy in Spodoptera exigua via the formulation of dsRNA with guanylated polymers. Front. Physiol. 2018, 9, 1-13. [CrossRef]

27. Akhtar, Y.; Isman, M.B. Generalization of a habituated feeding deterrent response to unrelated antifeedants following prolonged exposure in a generalist herbivore, Trichoplusia ni. J. Chem. Ecol. 2004, 30, 1349-1362. [CrossRef]

28. Liyun, R.; Ganghui, Z.; Bimei, C.; Longfei, H.; Yongmei, L.; Baoshan, C. Evaluation of ten botanical insecticides against the sweet potato Weevil, Cylas formicarius (Fabricius, 1798) (Coleoptera: Brentidae). Afr. J. Agric. Res. 2020, 16, 1531-1539. [CrossRef]

29. Nta, A.I.; Oku, E.E. Effects of Dennettia tripetalla (Backer), Xylopia aethiopica (Dunal) and Aframomum melegueta Schum Oils against the African Sweet Potato Weevil, Cylas puncticollis (Boheman). Asian J. Res. Zool. 2019, 2, 1-10. [CrossRef]

30. Ni, X.; Xu, W.; Blanco, M.H.; Williams, W.P. Evaluation of fall armyworm resistance in maize germplasm lines using visual leaf injury rating and predator survey. Insect Sci. 2014, 21, 541-555. [CrossRef]

31. Lourenço, A.M.; Haddi, K.; Ribeiro, B.M.; Corrêia, R.F.T.; Tomé, H.V.V.; Santos-Amaya, O.; Pereira, E.J.G.; Guedes, R.N.C.; Santos, G.R.; Oliveira, E.E.; et al. Essential oil of Siparuna guianensis as an alternative tool for improved lepidopteran control and resistance management practices. Sci. Rep. 2018, 8, 7215. [CrossRef]

32. Caballero-Gallardo, K.; Pino-Benitez, N.; Pajaro-Castro, N.; Stashenko, E.; Olivero-Verbel, J. Plants cultivated in Choco, Colombia, as source of repellents against Tribolium castaneum (Herbst). J. Asia. Pac. Entomol. 2014, 17, 753-759. [CrossRef]

33. Charleston, D.S.; Kfir, R.; Dicke, M.; Vet, L.E.M. Impact of botanical pesticides derived from Melia azedarach and Azadirachta indica on the biology of two parasitoid species of the diamondback moth. Biol. Control. 2005, 33, 131-142. [CrossRef]

34. Contreras-Cornejo, H.A.; del-Val, E.; Macías-Rodríguez, L.; Alarcón, A.; González-Esquivel, C.E.; Larsen, J. Trichoderma atroviride, a maize root associated fungus, increases the parasitism rate of the fall armyworm Spodoptera frugiperda by its natural enemy Campoletis sonorensis. Soil Biol. Biochem. 2018, 122, 196-202. [CrossRef]

35. Saxena, R.C. Antifeedants in tropical pest management. Int. J. Trop. Insect Sci. 1987, 8, 731-736. [CrossRef]

36. Tan, Q.G.; Luo, X.D. Meliaceous limonoids: Chemistry and biological activities. Chem. Rev. 2011, 111, 7437-7522. [CrossRef]

37. Vargas-Méndez, L.Y.; Sanabria-Flórez, P.L.; Saavedra-Reyes, L.M.; Merchan-Arenas, D.R.; Kouznetsov, V.V. Bioactivity of semisynthetic eugenol derivatives against Spodoptera frugiperda (Lepidoptera: Noctuidae) larvae infesting maize in Colombia. Saudi J. Biol. Sci. 2019, 26, 1613-1620. [CrossRef] [PubMed]

38. Silva-Aguayo, G.; Rodríguez-Maciel, J.C.; Lagunes-Tejeda, A.; Llanderal-Cázares, C.; Alatorre-Rosas, R.; Shelton, A.M.; Blanco, C.A. Bioactivity of boldo (Peumus boldus Molina) (Laurales: Monimiaceae) on Spodoptera frugiperda (J.E. Smith) and Helicoverpa zea (Boddie) (Lepidoptera: Noctuidae). Southwest. Entomol. 2010, 35, 215-231. [CrossRef]

39. Silva, G.; Rodríguez, J.C.; Blanco, C.A.; Lagunes, A. Bioactivity of a water extract of boldus (Peumus boldus molina) against Spodoptera frugiperda (J.E. Smith) and Helicoverpa zea Boddie (Lepidoptera: Noctuidae). Chil. J. Agric. Res. 2013, 73, 135-141. [CrossRef]

40. Paredes-Sánchez, F.A.; Rivera, G.; Bocanegra-García, V.; Martínez-Padrón, H.Y.; Berrones-Morales, M.; Niño-García, N.; HerreraMayorga, V. Advances in Control Strategies against Spodoptera frugiperda. A Review. Molecules 2021, 26, 5587. [CrossRef]

41. Nta, A.I.; Okweche, S.I.; Umoetok, S.B. Efficacy of Three Plant Powders in the Control of Cylas puncticollis (Boheman) (Coleoptera: Curculionidae) on Sweet Potato during Storage. Afr. Entomol. 2018, 26, 141-149. [CrossRef]

42. Akhtar, Y.; Isman, M.B. Comparative growth inhibitory and antifeedant effects of plant extracts and pure allelochemicals on four phytophagous insect species. J. Appl. Entomol. 2004, 128, 32-38. [CrossRef] 